\title{
HEGELS BEGRIFF DES ABSOLUTEN GEISTES
}

Wer fast nichts kennt von Hegels Philosophie, weiß wahrscheinlich doch, daß darin Kunst, Religion und Philosophie als absoluter Geist bezeichnet werden und daß Hegel diesen Geist unterscheidet von einem zuvor abgehandelten objektiven sowie einem noch früher thematisierten subjektiven Geist. Bekannt ist auch weithin, daß die einzige systematische Abhandlung dieses Ganzen nicht von Kunst, Religion und Philosophie überhaupt handelt, sondern speziell von der klassischen griechischen Kunst, der christlichen Religion und der neuzeitlichen europäischen Philosophie, die Hegel in seinem eigenen philosophischen Programm münden sieht. Was aber soll diese Konzentration auf je eine exemplarische Gestaltung von Kunst, Religion und Philosophie? Das wird im Folgenden nicht das Hauptthema sein. Denn es führt nicht auf den Begriff des absoluten Geistes, sondern betrifft erst die Entwicklung dieses Begriffs. Was aber macht den Unterschied des absoluten Geistes vom objektiven (und vom subjektiven) Geist aus? Warum besteht hier in Hegels Augen eigentlich ein grundsätzlicher Unterschied? Gibt es überhaupt einen absoluten Geist, und wenn ,ja" - wodurch können wir uns davon überzeugen? Darüber erfährt man selbst in umfangreichen Darstellungen der Hegelischen Geistphilosophie so gut wie nichts. Man vergleiche z.B. die über 550 Seiten umfassenden 28 einschlägigen Kapitel der Hegelmonographie von Kuno Fischer!

Mit der neueren Hegel-Literatur steht es in dieser Hinsicht nicht besser: Fast die einzigen, die den Gehalt und Anspruch von Hegels Philosophie des absoluten Geistes heutzutage einigermaßen ernst nehmen, befassen sich damit als christliche Theologen oder weil sie aus christlicher Glaubensüberzeugung philosophieren. Sie haben also überwiegend, wenn nicht ausschließlich Interesse an Hegels Deutung der christlichen Religion. Das bringt mit sich, daß man Argumente gegen einen „Finitismus" des Geistes, der ohne die Behauptung eines unendlichen Geistes auskommen möchte, hier vergeblich sucht. Wer etwas schon weiß, und sei's im Glauben, für den werden Gründe, aus denen man es erkennen kann, ziemlich witzlos. Er will es immer tiefer verstehen, ${ }^{1}$ kann sich damit aber auch begnügen.

${ }^{1}$ Am weitesten scheint mir darin Michael Theunissen gekommen. Seine Monogra- 
Ohne die Interessen philosophischer Deutung des christlichen Glaubens hat Hegels Lehre vom absoluten Geist (als solchem) derzeit fast keinen Kredit mehr. Das gilt nicht nur für die Marxistischen und Postmarxistischen Erben Hegels. Wie Jürgen Habermas jüngst treffend festgestellt hat ${ }^{2}$, besteht unter den zeitgenössischen Hegel-Spezialisten der USA die Neigung, den Begriff absoluten Geistes zu "deflationieren" zu demjenigen eines die ganze Menschheit einbeziehenden Grundes für intersubjektive Identitäten. Der absolute Geist wird dem objektiven Geist einer gemeinsamen Lebensform assimiliert.

Habermas ist fern davon, dem in der Sache entgegenzutreten. Er besteht nur darauf, daß damit eine ausdrückliche Hegel-Kritik verbunden werden muß. Auf deren wichtigste Punkte wird noch einzugehen sein. ${ }^{3}$ Zuvor aber sollte auf ein merkwürdiges Schwanken aufmerksam

phie (Hegels Lehre vom absoluten Geist als theologisch-politischer Traktat. Berlin 1970) macht sämtliche 25 Paragraphen der encyclopädischen Philosophie des absoluten Geistes, die meisten davon sogar einen nach dem anderen, zum Gegenstand einer über 200 Seiten umfassenden Exegese. (103-322) Doch Hegels Gründe für den Fortgang philosophischen Denkens vom objektiven zum absoluten Geist werden darin nicht wirklich aufgehellt. Es wird sogar darauf verzichtet, im Hegelischen Begriff des Geistes überhaupt die Ansätze für specifica des Begriffs eines absoluten Geistes aufzusuchen. Außer aus den vorherrschenden Interessen erklärt sich dies allerdings auch aus einer der Hauptthesen Theunissens: Hegels Philosophie des absoluten Geistes beruhe auf einem System, das durchweg geschichtsphilosophisch und desgleichen religionsphilosophisch konzipiert sei - ja sogar selber eine universale Geschichtsphilosophie und in seiner Ganzheit ebenso Religionsphilosophie. Geschichtsphilosophie sei bei Hegel gar keine besondere Disziplin. $(60,77)$ Wenn das Thema "Weltgeschichte" in Hegels "Encyclopädie" $^{\prime \prime}(\S \S 548-552)$ nicht als dasjenige einer besonderen philosophischen Disziplin gilt, ist es nicht der Mühe wert zu fragen, warum die Grenzen des Gegenstandes, mit dem man es bei diesem Thema zu tun hat, überschritten werden müssen. - Einig hingegen weiß ich mich mit Theunissen hinsichtlich seiner These, Hegels "Theorie des Absoluten" sei als Ursprungsphilosophie Emanzipationsphilosophie. (22) Auch in Verteidigung Hegels gegen den Einwand, dem Begriff des absoluten Geistes würden die Spuren seiner Herkunft aus den intersubjektiven Gestalten des objektiven Geistes abgestreift, bin ich mit Theunissen eins. Der Zusammenhang zwischen objektivem und absolutem Geist im Übergang vom einen zum anderen ist wahrlich keiner der Ausblendung aller Zeitlichkeit, Geschichtlichkeit, Intersubjektivität und emanzipatorischen Interessen.

${ }^{2}$ Wahrheit und Rechtfertigung. Philosophische Aufsätze. Frankfurt/M. 1999. 217 f.

3 Die von Habermas gegen Hegels Philosophie des absoluten Geistes erhobenen Einwände machen geltend: (1) Wir haben keinen Grund zu der Erwartung, in Ansehung der äußeren Natur lasse sich der naturwissenschaftliche "Objektivismus der beobachtenden Vernunft überwinden". - (2) Wir können nicht aus dem „Horizont unserer Sprache und unserer diskursiven Praktiken ausbrechen". - (3) Als einziges Modell für ein "höheres Subjekt", dem ein höheres Wissen zugeschrieben werden kann, steht im absoluten Geist nur noch das Fichtesche "Selbst" eines obskuren Selbstbewußtseins zur Verfügung. Hegels absoluter Geist verkörpert und perpetuiert Fichtes "Tathandlung" des sich selbst "setzenden" Ich. Das Zu-sich-kommen dieses absoluten Geistes wird just mit Hilfe jenes Begriffs von Subjektivität gedacht, den Hegel in seiner frühen Jenenser Zeit selber überzeugend kritisiert hat. (220-23) - (4) Die Leser, an die sich He- 
gemacht werden, das an Habermas' Einstellung zu Hegels Lehre vom absoluten Geist wahrzunehmen ist: Einerseits ist der Geist, mit dem sich eine philosophische Erkenntnislehre $\mathrm{zu}$ befassen hat, nach $\mathrm{Ha}$ bermas' Überzeugung bloß ein endlicher. Das kennzeichnet die Position, die oben als Finitismus des Geistes bezeichnet wurde. Andererseits aber und ungeachtet dessen soll laut Habermas "das spekulative Interesse" "auch nach der Metaphysik" seine "Würde" behalten. (223) Doch wer sich fragt, worin diese Würde denn bestehen mag und was sie von uns fordert, der wird nicht umhin können, sich auf Hegels Geistphilosophie näher einzulassen, als Habermas uns zumutet. Dabei wird sich schnell herausstellen, daß die Habermas'schen Einwände gegen Hegel gar nicht Hegels systematische Geistphilosophie als solche berücksichtigen, ja sogar den Begriff des absoluten Geistes völlig im Dunkeln lassen. Ein wenig genauer sollte man es mit der encyclopädischen Philosophie des Geistes bei Hegel schon nehmen, wenn der Philosophie des absoluten Geistes ihre Berechtigung begründetermaßen abgesprochen, dem spekulativen Interesse "nach der Metaphysik" aber seine "Würde" bewahrt werden soll. Nach dieser Devise wird im Folgenden verfahren. Zuvor aber ist Rechenschaft darüber abzulegen, warum man einen Finitismus des Geistes, wie ihn Habermas vertritt, meiden sollte.

\section{Finitismus des Geistes?}

Der endliche Geist, den wir als Menschen haben, der wir sogar sind und den wir in gewissen Hervorbringungen objektivieren können, ist der einzige Geist, den wir zweifelsfrei kennen. Warum also sollte man sich in der Philosophie, jedenfalls wenn es um epistemologische Fragen geht, nicht mit Begriffen begnügen, die diesen Geist betreffen und mit Behauptungen über ihn oder Präsuppositionen in Bezug auf ihn? Anderer Geist als der unsere, uns bekannte wäre dann höchstens

gel mit der Darstellung seiner Geistphilosophie wendet, sollen „konvertieren" "zur Erkenntnis einer alles bloß Subjektive überwältigenden Macht des Geistes", "die schicksalhaft über die Sphäre des Volksgeistes, also durch die Geschichte intersubjektiver Lebensformen hindurchgreift". - (5) Der intersubjektivistische Ansatz des jungen Hegel liefert seinerseits keinen gewichtigen internen Grund dafür, daß man ihn zugunsten des Konzepts eines Übergangs vom objektiven zum absoluten Geist aufgibt. (224-29) - (6) Beim Ubergang zum absoluten Geist werden dem Begriff des Geistes „die Spuren seiner Herkunft aus den intersubjektiven Gestalten des objektiven Geistes abgestreift". - Die Einwände (1) bis (6) werden mich in der Reihenfolge beschäftigen, in der sie hier angegeben sind. 
Gegenstand nachträglicher Vermutungen. Diese Erwägung ist auf den ersten Blick sehr plausibel. Bei näherem Zusehen aber stellt sie sich als irreführend heraus. Mindestens sechs Gründe sprechen dagegen, sich ihr anzuvertrauen.

1. Was bekannt ist, ist damit noch lange nicht erkannt. Um es zu erkennen, bedarf man klarer und deutlicher Begriffe. Die aber erlangt man in der Philosophie anders als in den Fachwissenschaften nicht, indem man Theorien bzw. Theoreme aufstellt, sie möglichst gut miteinander vernetzt und formale Beweise für sie liefert oder wenigstens Bestätigungen - sei's durch entsprechende, zuvor unbekannt gewesene Tatsachen, sei's via Einbettung in eine Axiomatik. Ergebnisse solchen Vorgehens werden, wenn das Vorgehen erfolgreich war, in der Philosophie vorausgesetzt und genutzt, hingegen nicht in Konkurrenz zu den Fachwissenschaften gesucht. Aber es gibt andere Bemühungen um Erkenntnis, die der Philosophie eigentümlich sind. Sie müssen sich vor allem auf Begriffe konzentrieren, welche die Fachwissenschaften (für ihre Unternehmen wohlweislich) im Dunkeln lassen. Verlangt ist, daß man diese Begriffe bestimmt macht - durch Abgrenzung und durch Integration (ihres vernünftigen Gehalts) in Begriffe von Komplexerem; so nicht zuletzt für den Fall einer Beschränkung der Erkenntnis auf Bekanntes, was immer es sei. Dessen Begriff ist also vom Begriff seines Anderen abzuheben, und sei dies Andere auch inexistent oder von bloß problematischer Existenz, Man entlastet sich in der Philosophie mithin, wenn man sich ans Bekannte hält, nicht von der Aufgabe, zusätzlich zu seinem Begriff, sobald es den zu klären gilt, auch den Gegenbegriff zu untersuchen, und sei's der eines Unbekannten oder Problematischen - in unserem Fall z.B. der Begriff eines unendlichen Geistes. Diesen Begriff unbestimmt zu lassen oder bloß vorauszusetzen ist einer philosophischen Erkenntnis unwürdig - nicht zuletzt, weil damit auch die Bestimmtheit für den Begriff eines endlichen menschlichen Geistes bloß vorausgesetzt und unausgemacht bleibt.

2. Wenn man sich ausschließlich an unseren endlichen Geist hält, soweit er uns bereits bekannt ist, so kann man in epistemologischer Hinsicht nicht umhin, sich für die Klärung speziellerer Begriffe auf zwei Arten von Erkenntnis zu beschränken: die theoretische, die durch Bildung von Theorien ausmacht, was der Fall ist (sei's generell, sei's im Einzelnen aufgrund von Gesetzen und erfüllten Anwendungsbedingungen für Gesetzesaussagen); und die praktische, die uns sagt, was (unter gewissen Normen durch willentliche Setzung und Ver- 
wirklichung von Zwecken) geschehen soll. Von beiden Erkenntnisarten ist leicht zu zeigen, daß sie sich antinomisch zueinander verhalten hinsichtlich einiger ihrer fundamentalen mentalen Bestimmungen und unter Umständen auch hinsichtlich ihrer Erfordernisse. Die Antinomieprobleme, die sich hier auftun, lassen sich innerhalb des Gegensatzes von theoretischer und praktischer Erkenntnis wahrscheinlich nicht lösen. Wir kommen also, auf die Alternative theoretischen oder praktischen Erkennens beschränkt, wohl nicht einmal zu einer konsistenten Exposition des Begriffs für den endlichen Geist. Oder wir müssen den Phänomenen Gewalt antun und die Bestimmungen unseres Begriffs von erkennendem Geist reduzieren zugunsten einer Definition, die einseitig die theoretische oder einseitig die praktische Erkenntnis favorisiert.

3. Wenn wir uns auf den endlichen Geist beschränken, der wir als Menschen sind, - was rechtfertigt dann eigentlich die Annahme oder gar Behauptung, daß nicht nur er der Erkenntnis auf adäquate Weise zugänglich ist, sondern auch von ihm Unterschiedenes, wie z.B. die Natur? Warum soll die Zugänglichkeit, falls sie überhaupt besteht, adäquater sein als diejenige, durch welche sich andere Arten von Lebewesen auszeichnen? Warum sollte sie, wäre sie nicht erkennbarerweise adäquater, höher zu schätzen sein als die Weisen, in denen Naturphänomene anderen Lebewesen zugänglich sind? Man sieht: Gerade indem wir unseren philosophischen Horizont verengen auf endlichen Geist, der zufälligerweise wir Menschen sind, oder diesen Geist gar von der Natur absondern (jedenfalls aber von allem, was vielleicht sonst noch Geist ist), setzen wir uns zurecht dem Verdacht einer Spezies-chauvinistischen Auffassung von Geist und Erkenntnis aus. Hingegen können wir uns von einer solchen Auffassung so fern wie nur möglich halten, wenn wir erkennend zunächst zu einem Geistbegriff gelangen, welcher der Differenz von endlichem und unendlichem Geist vorausliegt, und erst von ihm aus fortgehen zur Erkenntnis desjenigen Geistes, der wir als endliche Wesen sind.

4. Beschränkt auf die Alternative unseres theoretischen oder praktischen Erkennens können wir den endlichen Geist, der wir sind, nur als ein Seiendes (unter anderem Seienden, das von ihm verschieden ist) denken, so daß auch ein unendlicher Geist, den wir doch wenigstens als Problem denken müssen, dann nur als ein vom endlichen Geist verschiedenes Seiendes zu nehmen wäre. Damit aber wird der unendliche Geist nur noch in einer ihn verendlichenden Weise konzipiert. Denn Seiendes hat an anderem Seienden, wovon es sich unterscheidet, 
seine Grenze. Zudem aber macht gerade diese in sich defekte Weise, unendlichen Geist zu denken, von vornherein jeden Versuch, ihn zu erkennen, gegen leicht $\mathrm{zu}$ erhebende skeptische Einwände erfolglos. Der Ausgang vom Bekannten ist durch willkürliche Beschränkung also gar nicht so unvorgreiflich, wie er sich gibt.

5. Das Problem einer Philosophie des Geistes ist dessen Zusammenhang mit der Natur. Hinsichtlich seiner war die neuzeitliche Metaphysik in die größten Schwierigkeiten gekommen. Gilt es einen Dualismus von Natur und Geist zu lehren oder einen - sei's naturalistischen, sei's spiritualistischen - Monismus? Kein Glied dieser doppelten Alternative erlaubt eine überzeugende Position. Im Fall des Dualismus werden wir uns z.B. vergeblich fragen, wie und warum denn, gegeben das eine beider, das andere zu ihm hinzukommt; wie und warum die Natur als das eine von beiden der Erkenntnis seitens des anderen zugänglich sein soll und wie ein Teil der Natur - als Leib - mit einer lebendigen Vereinzelung des Geistes - als Seele - eine personale Einheit soll bilden können. Alle Versuche hingegen, unserem Freiheitsbewußtsein dualistisch gerecht werden zu wollen, setzen sich dem vernichtenden Spott Spinozas aus: sie wollen ein "imperium in imperio" (naturae) errichten. Im Fall des Monismus aber bleibt es ein unauflösliches Rätsel, warum unsere Begriffe für Naturales und Geistiges so verschiedenartig sind und sich so dauerhaft gegen Reduktion nach der einen oder anderen Seite hin sperren. Im Fall seiner spiritualistischen Variante müssen wir uns zudem bezüglich der Frage, ob die Außenwelt real ist, zu einem Idealismus bekennen, den schon der "transzendentale Idealist" Kant einen Skandal genannt hat und der gegen den Realismus der Naturwissenschaften nur durch fromme Hartnäckigkeit oder Reduktion der ganzen Philosophie auf einen eigensinnigen Phänomenalismus, wenn nicht gar Solipsismus zu behaupten ist. Gegen den naturalistischen Monismus aber wird sich immer unser praktisches Selbst- und Freiheitsbewußtsein sträuben. Fazit: Wir brauchen eine Philosophie des Geistes, die sowohl der Dualität von Natur und Geist Rechnung trägt als auch zwischen beiden (und zwar ebenso für den Geist überhaupt wie, in je spezifischer Weise, für den endlichen und den unendlichen Geist, wenn es ihn gibt) einen so engen Zusammenhang zu begreifen vermag, daß man nicht von Dualismus sprechen kann wie andererseits - wegen der Dualität - auch nicht von einem Monismus sei's der Natur, sei's des Geistes. Wenn Monismus, weil kein Dualismus -, dann jedenfalls weder einer der Natur noch einer des Geistes, nämlich einer der absoluten Idee. Aussicht, die Probleme zu bewältigen, 
in die sowohl die dualistischen wie die monistischen Konzepte geführt haben, besteht gewiß nur, wenn wir den Geist in seinem größtmöglichen Umfang berücksichtigen. Man wird diese Probleme nicht dadurch los, daß man keine Notiz von ihnen nimmt und sein Denken zu einem „nachmetaphysischen“ erklärt. Man legt diesem Denken mit einem Finitismus des Geistes lediglich Scheuklappen an.

6. Zwei der oben aufgelisteten Habermas'schen Einwände gegen Hegel lauten: (1) Der naturwissenschaftliche "Objektivismus der beobachtenden Vernunft" lasse sich nicht "überwinden", und (2) wir seien nicht imstande, aus dem „Horizont unserer Sprache und unserer diskursiven Praktiken" "auszubrechen“. Wenn das triftige Bedenken gegen Hegels Konzept eines absoluten Geistes wären, so träfen sie zweifellos auch schon den Ansatz der ganzen Hegelischen Geistphilosophie und wären ein wirkliches Hindernis, den Finitismus in der Philosophie des Geistes von Anfang an zu meiden. Aber die Bedenken beruhen, glaube ich, auf einem Mißverständnis. Hegels philosophisches Denken und begreifendes Erkennen soll nicht außerhalb des Horizonts unserer Sprache stattfinden. Es vollzieht sich innerhalb davon und soll eine genuin philosophische Diskurspraktik zum Einsatz bringen, die von bereits gängigen diskursiven Praktiken aus formulierund erreichbar ist: diejenige nämlich, in deren Ausübung das genuin philosophische Denken und Erkennen am Werk ist. Die Ausübung verlangt freilich, daß man sich mit Natur nicht nur in der Einstellung theoretischer Naturwissenschaften befaßt, wie wir das ja auch sonst nicht tun: z.B. im täglichen Leben, in ästhetischer Betrachtung und in religiösen Symbolhandlungen. Aber das heißt nicht, daß man dazu die naturwissenschaftliche Einstellung in sich oder gar in der institutionalisierten Fachwissenschaft „überwinden" müßte. Man darf die Betätigung dieser Einstellung nur nicht zum einzig vernünftigen Umgang mit der Natur und mit Natürlichem erklären. Ich sehe daher nicht, was uns vom Umgang mit der Natur her einen Finitismus des Geistes besonders empfehlen oder gar abnötigen würde. Die weiteren Einwände nämlich, die Habermas gegen Hegels Philosophie des absoluten Geistes erhebt, sind nicht stärker als die ersten beiden. Aber die Auseinandersetzung mit ihnen gehört in den Kontext des nächsten Abschnitts. 


\section{Vom objektiven zum absoluten Geist}

1. Hegels objektiver Geist versteht sich (im Unterschied zu demjenigen Diltheys ${ }^{4}$ ) nicht als Objektivation und intersubjektives Dasein irgendwelchen geistigen menschlichen "Lebens", sondern viel spezifischer als Zwecktätigkeit desjenigen freien Willens, welcher sich das Dasein seiner Freiheit zum Zweck gemacht hat. Allerdings ist die Freiheit dieses Willens in ihrer Tätigkeit der Zweckverwirklichung bezogen auf intersubjektive Verhältnisse von Willenstätigkeiten, die andere Zwecke verfolgen, wie auch auf intersubjektive Bewußtseinshorizonte und anthropologische, letztlich bedürfnisabhängige Relationen zwischen individuellen geistigen Subjekten. Aber nicht schon solche intersubjektiven geistigen Bezüge machen den objektiven Geist als solchen (und seine "Objektivität") aus. Konstitutiv ist hier vielmehr erst die zusätzliche Bestimmung, daß sich in den Bezügen der seine Freiheit bezweckende Wille (eines eben dadurch freien Geistes) objektiviert hat, so daß seine Freiheit damit in Form von Notwendigkeit gegeben ist für geistiges, individuell-menschliches und zwischenmenschliches Leben. (§§ 482-484) Der subjektive Geist geht der Objektivierung als Ausgangspunkt sowie äußerliches Material voraus. Ebenso wie er ist auch der objektive Geist, so verstanden, relativ auf etwas, das sein Anderes ist: eine als selbständig vorausgesetzte Natur. Im Unterschied aber zum subjektiven Geist bezieht sich der objektive in diesem Reflexionsverhältnis aktiv gerade auch auf das so vorausgesetzte Andere und nicht mehr nur auf sich selbst: Er setzt in dieser aktiven Beziehung die Natur als seine Welt. (§ 384) Natürlich aber ist er auch in dieser komplexen Aktivität ebenso wie der subjektive ein endlicher Geist ( $\S 385$ ): Er hat seine Schranke an der als selbständig vorausgesetzten Natur.

Von diesen Bestimmungen des subjektiven und des objektiven Geistes aus kann man gut verstehen, was der Ausdruck "absolut" im Terminus absoluter Geist primär besagt: Im Unterschied zu einem subjektiven oder objektiven, also wegen der genannten Voraussetzungen endlichen Geist ist ein absoluter Geist nicht mehr relativ zu einer ihm vorausgesetzten Natur, sondern davon abgelöst; und nicht mehr relativ auf die eine oder andere Seite des Gegensatzes von bloß subjektivem und bloß objektivem Geist, sondern auch von diesen einseitigen Beziehungen abgelöst. Aber das kann vorläufig vielerlei heißen: z.B. abgelöst von der Natur oder von ihrem Vorausgesetztsein; abgelöst von 
der einseitigen Relation zu subjektivem oder zu objektivem Geist durch eine doppelte Relation oder durch etwas anderes als bloße Relation, nämlich Einheit mit beiden Relaten; abgelöst vom einen oder anderen bloß durch Abstrahieren und Wegwerfen dessen, wovon abstrahiert wurde, oder aber durch Einheit des sich Ablösenden mit einem Umfassenderen, in welchem die Natur nicht mehr bloß vorausgesetzt, in welches sie vielmehr (zusammen mit dem endlichen Geist und seinen Relationen zu ihr) integriert ist; kurz: abgelöst nur in der Bedeutung "losgemacht von [...]" oder in der Bedeutung "frei gemacht $\mathrm{zu}[\ldots]$ und vollendet". Es wird gerade darauf ankommen, durch methodisch geregelten Fortgang des Denkens vom objektiven zum "absolut" genannten Geist auszumachen, was "absolut" hier des Näheren heißt und warum im Denken zu einem weiteren Begriff des Geistes zusätzlich zu dem des subjektiven und des objektiven Geistes - fortgegangen werden muß.

Längst vor dem Übergang vom objektiven zum absoluten Geist kann man sehen, daß ein "Ablösungsprozeß" wie der mit dem Ausdruck "absolut" zu denkende unter dem Hegelischen Begriff des Geistes überhaupt in der einen oder anderen Bedeutung möglich ist. Um die Begründung wenigstens anzudeuten: Der Geist wird durch spekulatives Begreifen in terminis der absoluten Idee als absolut Erstes der Natur erkannt. Er hat gemäß dieser Erkenntnis die Natur also nicht in jeder Hinsicht zu seiner Voraussetzung. Er ist ferner ein "Subjekt-Objekt", nämlich (in der Hegelischen Terminologie) die "zu ihrem Fürsichsein gelangte" absolute Idee, "deren Objekt [ihres Sich-Darstellens] ebensowohl als das Subjekt der Begriff ist". (§ 381) Er steht als solches Subjekt-Objekt gewiß nicht von vornherein wie ein selber Einseitiges in einseitiger Beziehung - sei's zu einem bloß subjektiven, sei's zu einem bloß objektiven Geist. Zu seinen grundlegenden begrifflichen Bestimmungen gehören verschiedene Weisen von Offenbar-machen ( $\delta \eta \lambda \hat{\varepsilon} \varepsilon v)$, durch die Erkenntnis allererst ermöglicht wird; und unter ihnen ist auch ein Offenbaren „im Begriff". In diesem "Offenbaren" wird die Natur ausdrücklich nicht mehr vorausgesetzt. Sie wird darin vom Geist, der ja das absolut Erste im Verhältnis zur Natur ist, „erschaffen" als Sein des Geistes, in welchem sich der Geist die Affirmation (also Bekräftigung) und Wahrheit (also Übereinstimmung mit sich) seiner Freiheit gibt. So mag es wohl sein, daß der Geist freigemacht wird (absolvitur) von jenen Relativitäten, die den endlichen, subjektiven und objektiven Geist auszeichnen.

Wenn irgend etwas, so ergibt dies bei Hegel das „Modell für ein hö- 
heres Subjekt", dem schließlich ein höheres Wissen als dasjenige bloß endlichen Geistes zugeschrieben werden kann. Doch ganz im Gegensatz zu Habermas' Behauptung steht dafür durchaus nicht das Fichtesche "Selbst" eines obskuren Selbstbewußtseins Pate - oder Fichtes "Tathandlung" des sich "setzenden" Ich. Daß Hegel nur dies zur Verfügung stehe, war ein weiterer (nämlich (3)) der Habermas'schen Einwände. Wer das „'höhere Subjekt" und sein Wissen ausfindig machen, aber auch feststellen will, was das spekulative Denken nötigt, vom objektiven Geist aus zu diesem Subjekt und Wissen fortzugehen, der sollte sich vor einem Mißverständnis hüten, das Habermas zu dem Einwand verleitet, man müsse, um vom objektiven zum absoluten Geist zu gelangen, (4) nach Hegel "konvertieren" (also eine Art religiöse Bekehrung vollziehen) zur Erkenntnis einer Macht des Geistes, die "alles bloß Subjektive überwältigt" und zudem "schicksalhaft" über die Sphäre des Volksgeistes hinweg durch die Geschichte intersubjektiver Lebensformen hindurchgreife. Die "Konversion " ${ }^{\prime 5}$ wird uns angeblich von Hegel abverlangt, $u m$ das Vertrauen zu tragen, daß die Geschichte im Ganzen der Vernunft unterworfen und die sittliche Wirklichkeit der modernen Welt "ohne unser Zutun" im Begriff ist, vernünftig $\mathrm{zu}$ werden. Dieses geschichtsphilosophische Vertrauen wiederum soll Hegel deshalb nötig scheinen, weil eine Kultur, die sich auf dem Weg der Revolutionierung von Staat und Gesellschaft neue Grundlagen schaffen will (wie Protagonisten der Französischen Revolution es wollten), sich selbst überfordern würde. (226 f.) Daran ist fast kein wahres Wort. Aber das vorliegende Thema erlaubt es hier nur anzudeuten, was nicht stimmt:

Zum einen bringt Habermas mit dem "weil" und "um zu" die Ordnung der Erkenntnisgründe in der Hegelischen Philosophie der Sittlichkeit völlig durcheinander. ${ }^{6}$ Zum anderen bedarf es gar nicht der

5 Sie wird bei Habermas auch „Konstruktion" eines Übergangs vom objektiven zum absoluten Geist genannt.

6 An der Französischen Revolution wird von Hegel nicht verurteilt, daß sich ihre Protagonisten mit der revolutionären Selbstkonstitution einer Kultur "überfordert" haben, sondern daß die "Kultur", die mit ihren Abstraktionen allenfalls zustande zu bringen war, keine sittliche sein konnte. Aber selbst wenn eine sittliche Kultur von ihnen intendiert gewesen wäre, also eine Überforderung vorgelegen hätte, wäre nach Hegel nicht deshalb das Vertrauen nötig, daß es in der sittlichen Welt vernünftig zugegangen ist und zugeht. Nötig, d.h. vom philosophischen Denken verlangt, ist hier auch gar nicht ein Vertrauen, sondern Einsicht. Und die wird nicht der Erfahrung einer Selbstüberforderung der französischen Revolutionäre verdankt, sondern begreifender Erkenntnis dessen, was sich aus der erscheinenden Dialektik der Endlichkeit individueller Staaten begrifflich ergibt. Die philosophische Einsicht (und das von ihr bestärkte Ver- 
„Konversion", für die sich Habermas die erwähnte, angeblich Hegelische Begründung zurechtlegt. Es geht nämlich hier gar nicht um Erkenntnis einer "alles bloß Subjektive überwältigenden Macht" (des Geistes). Weder der schlechthin allgemeine sittliche Geist, "Weltgeist" genannt, noch der absolute Geist ist eine solche Macht. Wie könnte der Weltgeist andernfalls objektiver Geist, also Objektivation freien subjektiven Geistes sein, der Begriff des absoluten Geistes aber bereits im freien Geist bestehen? ${ }^{7}$ Die Macht schließlich, welche der Weltgeist in der Tat ist, übergreift die Sphären der Volksgeister gerade nicht „schicksalhaft". Geschweige denn kann dies vom absoluten Geist gesagt werden, der ja vom Weltgeist aus (als Ergebnis eines Loslösungsprozesses) zu denken ist, aber ihm nicht wie ein Schicksal in die Parade fährt.

Genug der Polemik! Man muß Habermas zugute halten, daß der Gedanke, der über den objektiven zum absoluten Geist hinauszugehen nötigt, von Hegel in einen einzigen Paragraphen zusammengezwungen wird, der wahrlich nicht leicht zu verstehen ist.

2. Um zu verstehen, muß man sich klar machen, daß Hegels Philosophie der Weltgeschichte nicht nur von Sittlichkeit (und den anderen Themen der Rechtsphilosophie) handelt, sondern auch schon von $R e-$ ligion und Verwandtem, wenn auch noch ohne einen abgeleiteten und berichtigten Begriff davon, also nur in einer vorläufigen Bedeutung des sie bezeichnenden Ausdrucks: als Bewußtsein all dessen, was den Menschen, welche in einem sittlichen Ganzen zusammenleben, als das Höchste und zugleich als Grund ihrer Sittlichkeit gilt; aber solches Bewußtsein nicht bloß äußerlich (wie von etwas, das man kennt), sondern als innere, subjektive Gesinnung diesem Höchsten gegenüber. Darum gehört zu solchem Bewußtsein bei dem, der es hat, auch ein Sich-Erheben zu diesem Höchsten. Es kann verschiedensten Anlaß haben, kann ganz momentan, ja selbst bewußtlos geschehen ${ }^{8}$, aber auch eine bewußte religiöse Handlung sein, individuell oder kollektiv vollzogen. Auf die ganze Weltgeschichte gesehen ist das abstrakte Konzept solchen Sich-Erhebens mehrfach unbestimmt: nicht nur hinsichtlich

trauen), daß Vernunft in der Weltgeschichte am Werk war und in der Gegenwart am Werk ist, wird auch nicht davon "getragen", daß ein Übergang vom objektiven zum absoluten Geist konstruiert wird. Die Einsicht hat solches Getragen-werden so wenig nötig, daß sie (und nach Hegels Auffassung auf philosophisch überzeugende Weise sogar nur sie) vielmehr umgekehrt allererst zum Übergang vom objektiven in den absoluten Geist hinführt.

7 Vgl. $\$ 482$.

8 Vgl. Notizen zu Hegels Encyclopädie, § 453. In: Hegel-Studien 9 (1974). 16. 
des subjektiv-geistigen Mediums, in welchem die Erhebung stattfindet - im Erleben, Gefühl, Bewußtsein, in der Anschauung, Einbildung, im Denken. Das Konzept ist unbestimmt auch hinsichtlich des den Ausgangspunkt bildenden geistigen Gehalts und dementsprechend nicht weniger hinsichtlich des Endpunkts, zu dem der sich Erhebende gelangt. Gerade auch in ausgebildeten Lebensformen einer Religion kann die Erhebung schlicht „ein Wegwerfen, nur bey Seite setzen [...] des Endlichen"9 sein, von welchem dabei ausgegangen wird. Ferner kann denen, die diesen Schritt vollziehen, dadurch nicht nur Wahres zuteil werden, sondern auch Unwahres, für wie wahr sie es immer halten mögen. Aber es muß sich nicht allemal um Unwahres handeln, wenn gilt, was wir vom Geist als solchem oben registriert haben.

Sollte im philosophischen Denken die Sphäre des objektiven Geistes zu überschreiten sein (und mit ihr auch die Schranke des subjektiven Geistes), so wird dies zweifellos zu geschehen haben in Thematisierung des einen oder anderen Sich-Erhebens, von dessen mannigfaltigen Vorkommnissen uns die Historie Kenntnis gibt. Und der Überschritt, welcher der $\mathrm{zu}$ thematisierenden Erhebung philosophisch nachdenkt, wird dann wohl auch selbst den Charakter eines Sich-Erhebens (zu dem, was dem philosophischen Denken das Höchste ist) haben. Für den Fall der Unumgänglichkeit aber kann der Überschritt nicht so unbestimmt sein wie die Erhebung nach dem bisherigen, aus der Historie geschöpften Konzept. Es muß sich wohl beide Male (bei der zu thematisierenden und der philosophierend zu vollziehenden Erhebung) um ein Denken handeln und in ihm nicht bloß um ein beliebiges Wegwerfen und Beiseitesetzen des Ausgangspunktes, sondern um ein Verfahren mit formell bestimmtem Charakter: dem einer Tüchtigkeit, den Inhalt des Ausgangspunktes auf eine dem bloßen Zufall oder Belieben entzogene Weise zu bearbeiten und dadurch zu einem nicht zufälligen, sondern inhaltlich bestimmten Endpunkt zu gelangen. Desgleichen aber auch um einen Ausgangspunkt, der bezüglich seiner inhaltlichen Bestimmtheit kein beliebiger ist. Die Frage ist also, worin dieser Ausgangspunkt besteht, was den formellen Charakter des zu thematisierenden Denkens ausmacht und was sich diesem Charakter gemäß, aber auch aus Gründen, die mindestens dem philosophischen Denken einsichtig sind, für den Endpunkt an inhaltlicher Bestimmtheit ergibt. Was gibt unser Text (§ 552) und sein Umfeld zur Beantwortung dieser Frage an die Hand?

9 Ebd. 
Wie man auf den ersten Blick sieht, ist im Text (sogar zweimal) ein denkendes Sich-Erheben behauptet. Es wird auch (gleich mit dem ersten Satz beginnend) der Zustand beschrieben, von dem aus das SichErheben erfolgt: Der Volksgeist enthält Natur-Nothwendigkeit, und steht in äußerlichem Daseyn (§ 483); die in sich unendliche sittliche Substanz ist für sich eine besondere und beschränkte ( $§ 549 . u$. 550), und ihre subjective Seite mit Zufälligkeit behaftet, bewußtlose Sitte, und Bewußtseyn ihres Inhaltes als eines zeitlich Vorhandenen und im Verhältnisse gegen eine äußerliche Natur und Welt.

Am Ende wird dasjenige gekennzeichnet, zu welchem sich das Denken schließlich erhebt, das Ende des Sich-Erhebens also: Es ist Wissen des absoluten Geistes, als der ewig wirklichen Wahrheit, in welcher die wissende Vernunft frei für sich und die Nothwendigkeit, Natur und Geschichte nur seiner Offenbarung dienend und GefäBe seiner Ehre sind.

Die Charakterisierung des Ausgangszustands ist keine beliebige, sondern gibt uns die Charakteristika der Sittlichkeit, wie von dieser erkannt ist, daß sich (an ihr) eine Weltgeschichte vollziehen mußte. Allen Bestimmungen, die den Ausgangszustand beschreiben, kann man Gegenstücke in den Bestimmungen zuordnen, die den Endpunkt charakterisieren, und den meisten Ausgangsbestimmungen sogar Gegenstücke in Hegels eigenen Worten. ${ }^{10}$ Wir haben es mithin, wenn der Gang vom Anfang zum Ende begründet ist, nicht mit Unbestimmtem zu tun, sondern mit etwas Wohlbestimmtem; nicht mit beliebig Bestimmtem, sondern mit etwas, das erkennbarerweise so bestimmt sein muß, wie es charakterisiert ist; vor allem aber der zentralen Inhaltsbestimmung nach nicht mit Unwahrem, sondern mit Wahrem, ja mit der Wahrheit, sogar der "ewig wirklichen" - und dies als Resultat eines Denkens, dem wir von der in ihrem Wesen erkannten Sittlichkeit aus mit dem philosophischen Denken folgen können; das Resultat ist auBerdem das einzige und ist die einheitliche Variante an Vollendung, auf welche dieses Denken erkennbarerweise angelegt ist. Falls die Begründung gelingt, begreifen wir, daß und wie "die wahrhafte Religion und wahrhafte Religiosität" "hervorgeht" "aus der Sittlichkeit", die wir zuvor begriffen haben. ( $\$ 552 \mathrm{~A}, 2)$ Wir haben damit den nach Hegels Auffassung einzigen internen Grund für einen Übergang vom ob-

10 Das ist im Anhang übersichtlich zu machen versucht. Es braucht hier nicht Punkt für Punkt durchgegangen zu werden. Die Pendants im Endpunkt bilden zu den entsprechenden Ausgangsbestimmungen entweder einen Gegensatz $(G)$ oder sozusagen eine Vollendungsvariante (V), charakteristischerweise aber nur eine einzige. 
jektiven zum absoluten Geist identifiziert. Diesen Grund scheint Habermas gänzlich übersehen zu haben. Anders nämlich macht es keinen Sinn, (5) einzuwenden, der intersubjektivistische Ansatz des jungen Hegel liefere keinen gewichtigen internen Grund dafür, daß man ihn aufgibt zugunsten des Konzepts eines Übergangs vom objektiven zum absoluten Geist. Wir hingegen können im Vorgriff auf alle weiteren Ausführungen zum absoluten Geist aus diesem Grund auch schon entnehmen, welche Absicht Hegel mit der späteren Konzentration auf klassische griechische Kunst, christliche Religion und neuzeitliche Philosophie verbindet: Er wird uns erweisen wollen, daß absoluter Geist im vollen Sinn seines Begriffs sich nur Wissensgestalt gibt als die wahre Kunst, als die wahrhafte Religion und als diejenige Philosophie, die Wissenschaft ist; und daß diese drei nur zu finden sind in der klassischen griechischen Kunst, der christlichen Religion und der neuzeitlichen Philosophie. Fehlt nur das Wichtigste: die Begründung mit Hilfe einer näheren Auskunft über das Denken, das vom Ausgangs- zum Endpunkt führt.

3. Wie schon gesagt, soll es sich um zweierlei Denken oder zweierlei Tätigkeit eines Denkens handeln. Subjekt der Tätigkeit soll im einen Fall der in der Sittlichkeit denkende Geist sein, im anderen Fall hingegen der denkende Geist der Weltgeschichte. Was aber ist die Struktur ihrer denkenden Tätigkeit? "Denken" in allgemeinster Bedeutung dieses Ausdrucks ist für Hegel das Haben voh Gedanken (§ 465) und deren erkennende Wirksamkeit im Urteilen oder Schließen. (Vgl. § 467.) Das ist für unseren Kontext natürlich zu unbestimmt. Das Denken soll ja nun eines in der Sittlichkeit und ein Denken der Weltgeschichte sein; und es soll den schon festgestellten Ausgangspunkt haben. Die Anmerkung zu $\S 552$ macht uns darauf aufmerksam, daß in $\S 50 \mathrm{~A}^{11}$ bereits Näheres über den formellen Charakter dieses Denkens als einer „Erhebung des Geistes zu Gott” gesagt wurde. Doch daß etwas wie eine solche Erhebung nun im philosophischen Denken vollzogen werden muß, wollen wir ja allererst einsehen. Wir können aus jenen Bemerkungen daher allenfalls entnehmen, was schon auf den in der Sittlichkeit denkenden Geist und den denkenden Geist der Weltgeschichte zutrifft. Hierzu gehört zweifellos, daß das Denken, um das es nun zu tun ist, die (sittliche) Welt auf ihr Wesen, ihre Substanz hin betrachtet und daß diese Substanz sich im Denken als die allgemeine Macht und

11 Im gedruckten Text: $\S 51$ A. Aber das ist zweifellos ein Druckfehler oder ein Versehen. 
Zweckbestimmung der sittlichen Welt herausstellt. Der Form nach hat dieses Denken den Charakter eines Schlusses, den Peirce "Abduktion" genannt hat: Es wird von der Beschreibung eines Wahrgenommenen, sinnlich Gegebenen aus, nämlich gegebenen sittlichen Verhältnissen, (via Rückgang in die bestmögliche Erklärung) zurückgeschlossen auf ein nicht Wahrnehmbares, das den inneren Gehalt des Wahrgenommenen ausmacht - oder dessen Wesen, das in der Conclusio mit Negation und Entfernung des Äußerlichen, Wahrnehmbaren herausgehoben wird. (Vgl. $\S \S 13,23$.

So kommt's für den in der Sittlichkeit denkenden Geist dazu, daß dieser, wie behauptet, sich zum Wissen seiner in seiner Wesentlichkeit erhebt. Die denkende Betrachtung der Weltgeschichte belehrt uns darüber, daß diesem Geist qua Denken das Produzieren von geistigen Erzeugnissen charakteristisch ist, in denen ihm seine wahrhafte Natur zum Vorschein kommt. Aber die historische Belehrung ist tief in der erkannten Struktur der Sittlichkeit verankert. Die Sittlichkeit nämlich ist ihrer Idee nach (deren Am-Werk-Sein mit dem Staat erreicht ist) die Erweiterung ${ }^{12}$ des besonderen substantiellen Willens zum wahrhaft allgemeinen Willen einer in sich unendlichen sittlichen Substanz. Unter Berücksichtigung der Struktur der Weltgeschichte ist dem hinzuzufügen: Bei welcher relativen Allgemeinheit das sittliche Denken innerhalb einer konkreten sittlichen Welt mit der immanenten Beschränktheit eines Volksgeistes immer stehen bleiben mag, - dieses Denken gelangt im Zuge der genannten Erweiterung doch auch zu einem wissenden Bewußtsein von dem, was für seine sittliche Welt wesentlich ist; und es gelangt mit diesem Für-sich-Werden des Wesens formell auch bereits über das bloß (wissende) Wollen und In-der-Sitte-Stehen hinaus. In diesem Sinn sagt die Anmerkung zu § 552, die Sittlichkeit sei denkende als "der freien Allgemeinheit ihres konkreten Wesens bewußt werdende". (Abs. 2) Die Notizen zur Heidelberger "Encyclopädie" $^{\prime \prime}($ 453) machen darauf aufmerksam, daß dies in weltgeschichtlichen Betrachtungen am historischen Material studiert werden kann ${ }^{13}$ : "Dichter, Philosophen erfassen" - „in Gedanken ihres Volkes" - „die Idee, die ihnen durch den Weltgeist bestimmt ist".

Der denkende Geist der Weltgeschichte hat wohl denselben, schon an-

12 Vgl. Hegels Philosophie des Rechts. Die Vorlesung von 1819/20 in einer Nachschrift. Hrsg. v. Dieter Henrich. Frankfurt/M. 1983. 207 f.

13 A.a.O. 17. Vgl. auch die paradigmatische Bezugnahme auf Plato und die griechischen Dichter in $\S 552$ A, 7 ff. und Die Vernunft in der Geschichte. Hrsg. v. J. Hoffmeister. Hamburg 1955. $177 \mathrm{ff}$. 
gegebenen Ausgangspunkt wie der in der Sittlichkeit denkende (und in ihren jeweiligen Schranken verbleibende). Sein Denken ist für Hegel vermutlich auch kein schlicht anderes als dasjenige des in der Sittlichkeit denkenden Geistes, sondern eine Spezifikation davon: Es hebt in sich die jeweilige Schranke des in der Sittlichkeit denkenden Geistes auf und vermag dies zu leisten, da die Schranke eine des objektiven, nicht eine des subjektiven Geistes ist; es geht also auf ein schlechthin Allgemeines zu, das als Idee alle besonderen Prinzipien der sittlichen Wirklichkeit in sich enthält. Aber es ist gründlich zu überlegen, in welchem Sinn hier von solcher Allgemeinheit zu reden ist. Zunächst gilt mindestens, daß dieses Denken seine Struktur mit derjenigen des Weltgeistes teilt. Es erhebt sich nicht nur zum Wissen seiner in seiner jeweiligen Wesentlichkeit; sondern das Erfassen seiner je besonderen konkreten Allgemeinheit ist ihm - gemäß der Struktur des Bewußtseins - im Stadium von Vollendung, das weltgeschichtlich allemal erreicht wird, auch ein neues Sich-Auslegen auf höherer Allgemeinheitsstufe seines Prinzips; und auf dieser Stufe nicht nur wiederum Erfassen des neu Ausgelegten, sondern auch ein tieferes Erfassen des vorherigen Erfassens. ( $R$ § 343) Der Weg dieses Denkens führt darum nicht nur zum Erfassen immer höherer und konkreterer Allgemeinheit im Sinn einer Allgemeinheit für immer größere Sittlichkeits- und Volksgeistbereiche. Das Denken, das ihn zurücklegt, geht auch in sich und geht aus der Objektikität des Geistes zurück in den freien Geist, der schon als der Begriff des absoluten Geistes (wenngleich noch in Abstraktion von der Objektivität) erkannt wurde. (§ 482) Die Allgemeinheit ist nicht nur eine über größtmöglichem Umfang an (objektiver) Sittlichkeit, sondern auch eine über größte Tiefe der Subjektivität sittlicher Subjekte, die freier Geist sind. Man muß daher auch sagen, daß dieses Denken zuläuft auf ein Sich-Wissen des Geistes, das nicht mehr ausschließlich dem sittlichen Willen (qua zwecksetzender und -verwirklichender Aktivität) immanent ist; daß es also die Sphäre der Sittlichkeit überschreitet. ${ }^{14}$

Aber wenn das Gesagte den denkenden Geist der Weltgeschichte charakterisiert und deren Fortschritt doch in die Gegenwart mündet (mit einem nur vorläufigen Ende der Geschichte, das über sich hinausweist in unbestimmte Zukunft der Sittlichkeit), warum soll dann das Denken, mit dem wir es jetzt zu tun haben, gleichwohl die Sittlichkeit in toto überschreiten und zum Wissen eines Geistes kommen,

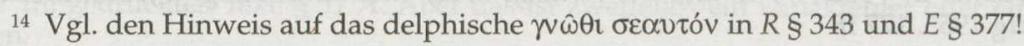


der von den Relativitäten des objektiven sowie des subjektiven Geistes losgelöst, also absolut ist? Die Antwort wird vorbereitet in der schon erwähnten Anmerkung ( $(50)$ zum Formellen der denkenden Erhebung. Dort ist Hegel auf jenes Transzendieren zu sprechen gekommen, das für alle Gottesbeweise erforderlich ist, am offenkundigsten aber für den kosmologischen Gottesbeweis (e contingentia mundi). Er hat darauf hingewiesen, daß das Hinausgehen über alles Sinnliche (zum Unendlichen und Übersinnlichen) geschehen muß durch einen Sprung und daß dieser Sprung nur im Denken vollzogen werden kann. Falls er in der Form eines Schlusses vollzogen werden soll, muß dieser Schluß in der Conclusio mindestens eine der Prämissen hinsichtlich ihres begrifflichen Gehalts destruieren; und falls der zu vollziehende Übergang zurückführen soll vom Vielen zum Einen, muß der Schluß einer sein, in dessen Vermitteln (der Conclusio sowie der PrämissenTerme) sich sogar Übergang und Vermitteln aufheben. An späterer Stelle hat Hegel dann dargetan, daß und warum es nach seiner Auffassung solche Schlüsse gibt und daß sie sogar eine vorzügliche Vernünftigkeit besitzen. (§ 192)

Warum aber soll ein solcher Schluß in unserem Fall (des denkenden Geistes der Weltgeschichte) unumgänglich sein? Die Frage ist zu konkretisieren: Warum muß das Denken dieses Geistes (der doch bis jetzt als allgemeiner Geist der sittlichen Welt, also Weltgeist, zu denken ist) das in seinen Prämissen enthaltene Konzept einer sittlichen Welt, ja sogar das Konzept von Welt überhaupt (als einem Compositum aus Natur und endlichem Geist) überschreiten? Die Frage spitzt sich daraufhin zu, warum das Denken bei keinem Zweck des Willens stehen bleiben kann. Damit aber wird die Frage beantwortbar und das Erkenntnisproblem lösbar, das wir mit ihr haben. Denn mit dem umrissenen Konzept schlechthinniger Allgemeinheit müssen wir die Weltgeschichte (als die bisher umfassendste Zweckverwirklichung des an und für sich freien Willens) in der Idee denken. In der Idee aber, die nach Maßgabe der spekulativen Logik aus der äußeren Teleologie hervorgeht, ist alles äußerliche Material für die Zwecktätigkeit des Willens zusammengeschlossen mit dieser Zwecktätigkeit und ihrem Objekt sowie Subjekt; und das Subjekt der Zwecktätigkeit mit sich selbst zusammengeschlossen - gemäß der Form eines Schlusses wie des erwähnten Schlusses "der Notwendigkeit" (in Form einer Vermittlung nämlich durch Aufheben der Vermittlung) als ein "ZusammenschlieBen des Subjekts nicht mit Anderem, sondern mit aufgehobenem Anderen, mit sich selbst". (§ 192; vgl. § 204 A, 4) Nun liegt die Lösung 
Lösung unseres Erkenntnisproblems auf der Hand: Zum „Material" der Zweckverwirklichung gehört hier nicht nur das anthropologische Material menschlicher Bedürfnisse und das weite Gebiet intersubjektiver Beziehungen von Individuen und Institutionen, die endlicher Geist sind. Es gehört dazu auch die Natur (im Bewußtseinshorizont des willentlich Handelnden) als ein selbständiges Ganzes, das Voraussetzung sowohl des subjektiven wie des objektiven Geistes ist. Bei dieser Voraussetzung kann es somit nicht mehr bleiben. Das Wissen also, zu dem wir von der umfassendsten, unter den höchstmöglichen Willenszweck (der Freiheit) gestellten äußeren Teleologie mit dem Übergang zur Idee gelangen, ist vielleicht auch noch dem Willen in seinem subjektivsten, aller Zwecksetzung vorausliegenden Inneren immanent; aber es ist jedenfalls nicht mehr beschränkt auf Willenszwecke, die allemal endliche sind. Das Wissen ist selbst wieder freier Geist sowie Sich-Wissen; aber nun nicht mehr in Abstraktion vom objektiven Geist, sondern konkretisiert, d.h. zusammengewachsen mit dessen voller Entfaltung bis zur Gegenwart, also in Einheit mit ihm. Sein Subjekt sowie Objekt ist von den oben genannten Relativitäten endlichen Geistes abgelöst, also absoluter Geist. Man versteht somit, daß dieser Geist hinausgeht „über das Aggregat von Endlichkeit, welches Welt genannt wird". (§50 A, 2)

Aber als Geist, der in denkender Erhebung des endlichen freien Geistes $z u$ ihm gedacht ist, ist er nicht ein diesem endlichen Geist fremdes, jenseitiges Unendliches, sondern im Sich-Wissen eine schwierig zu beschreibende wechselseitige Durchdringung von endlichem und unendlichem Geist. Das wird zum Schlüssel für die Exposition des Begriffs absoluten Geistes werden. (§ 554) Doch schon jetzt läßt sich sagen: Als Subjekt seines Sich-Wissens ist der absolute Geist nicht mehr die zeitliche Wahrheit des Gedankens, der über die Beschränktheit eines Volksgeistes zu einem allgemeiner verfaßten, gleichwohl aber noch beschränkten, anderen Volksgeist hinausgeht und - als Vernunft in der Geschichte - diesen Übergang bewirkt; sondern er ist eine Wahrheit (d.h. Übereinstimmung des Gedankens mit sich), die ewig wirklich ist, da sie auch "über" der Natur und somit über der Zeit steht. Im Wissen, als der Tätigkeit dieses Subjekts, ist die Vernunft frei für sich. Aber wir befinden uns mit dem Denken nicht in einem kosmologischen Gottesbeweis. An die Stelle der sittlichen Welt und Welt überhaupt ist darum nun nicht ein zweckloses ens necessarium getreten. Vielmehr ist (gemäß der spekulativen Logik) eine innere Teleologie zum Vorschein gekommen just an dem, womit wir schon längst befaßt sind, d.h. an 
der Natur und am endlichen Geist. Man hat daher keinen Grund mehr $\mathrm{zu}$ protestieren, wenn noch gesagt wird, daß diese beiden mit ihrer Notwendigkeit der "Offenbarung" des Geistes dienen. Das "Offenbaren im Begriff" gehört ja schon zu dessen Ausgangsbestimmung. Nun wird die Realisierung dieser Ausgangsbestimmung als Sollzustand der zutage getretenen inneren Teleologie erkannt, in welcher an die Stelle eines Willenszwecks Kantisch gesprochen eine "Zweckmäßigkeit ohne Zweck" getreten ist. Wenn man bedenkt, was in der Philosophie der Weltgeschichte über den Ruhm ausgemacht wurde, den weltgeschichtlich bedeutsame Taten ihren Tätern verschaffen, kann man sogar sagen: Wer sich zum Wissen des absoluten Geistes erhebt, der läßt sich nicht vom Ruhm weltgeschichtlicher Individuen blenden oder dazu verleiten, mit seinem zufälligen Schicksal zu hadern. Er gibt dem Höchsten die Ehre. Er kann dies auch, da ihm die Natur und Geschichte "Gefäße", d.h. Behälter und Ausflußpotentiale zu bezeugender Ehrerbietung sind; und er hat sich zu einem Geist erhoben, den er sich als Macht vorstellen kann, solche "Gefäße der Ehre" "aus einem Klumpen" zu schaffen. ${ }^{15}$

Man beachte aber, daß der Gedanke, der zu diesem Ergebnis führte, im Gegensinn zur Richtung des physikoteleologischen Gottesbeweises verlief und auch inhaltlich $\mathrm{zu}$ ihm unter mehreren Gesichtspunkten einen Gegensatz bildet. In diesem „Beweis" wird ausgegangen von einer Prämisse, welche eine teleologisch geordnete Natur und natürliche Welt behauptet, aber bestenfalls problematische Wahrheit beanspruchen kann; geschlossen wird auf einen unendlichen Verstand, der diese Ordnung verursacht hat, so daß die Teleologie bloß eine äußere ist und das (vermeintlich) Bewiesene die Existenz eines außerweltlichen, von uns verschiedenen Geistes. Das Hegelische Argument hingegen geht im Ausgang von der assertorischen, durch Naturphilosophie sogar apodiktisch gemachten Behauptung einer nicht-teleologisch bestimmten Natur und einer willentlichen, aber nicht willkürlichen Zwecksetzung endlichen Geistes ohne Verursachungskonzept schlüssig fort zur inneren Teleologie einer Einheit von unendlichem Geist, endlichem Geist und Natur.

Bleibt ein letzter Punkt wenigstens anzudeuten: Die skizzierte Reproduktion des Hegelischen Arguments mußte den Eindruck er-

15 Vgl. Paulus im Römerbrief 9, 20 f.: „Ja, lieber Mensch, wer bist du denn, daß du mit Gott rechten willst? Spricht auch ein Werk zu seinem Meister: Warum machst du mich so? Hat nicht ein Töpfer Macht, aus einem Klumpen zu machen ein Gefäß zu Ehren und das andre zu Unehren?" (Den Hinweis, daß Hegel hierauf anspielt, verdanke ich Gerd Theißen.) 
wecken, das Denken des Geistes der Weltgeschichte, dem sich der Übergang vom objektiven Geist zum Wissen des absoluten Geistes (und damit auch zu diesem selbst) verdankt, könne nur das in der $\mathrm{He}$ gelischen Philosophie selber betätigte Denken sein. Für eine explizite Version dieses Denkens trifft das der Sache nach (und wohl auch nach Hegels Auffassung) zu. Doch die explizite Version basiert in Hegels weltgeschichtlicher Betrachtung auch auf einer impliziten Version, die innerhalb des römischen Weltreichs der untergehenden antiken Sittlichkeit zur Existenz gekommen ist. Wie ist dieses implizite Denken des Geistes der Weltgeschichte als Basis der expliziten Version zu verstehen? Kann es als zusätzliches Argument zugunsten der behaupteten Notwendigkeit dienen, im philosophischen Denken vom objektiven zum absoluten Geist überzugehen? Das wäre erst noch auszumachen. Wer es ausmachen wollte, müßte auch darlegen, was es besagen soll, wenn Hegel an prominenter Stelle behauptet, alle Bildung und Philosophie, Religion und Wissenschaft habe auf den Punkt hingedrängt, nicht nur zu entdecken, daß das Absolute der Geist ist, sondern auch den Sinn und Inhalt dieser Definition zu erfassen; und allein aus diesem Drang sei die Weltgeschichte zu begreifen. Darauf wird hier nicht mehr eingegangen.

Was ergibt sich aus der obigen Interpretation des $\S 552$ ? Soweit sie gediehen ist, mindestens viererlei:

1. Unter Voraussetzung der Hegelischen Logik, Naturphilosophie, Exposition des Geistbegriffs und Philosophie des endlichen Geistes ist Hegels Begründung für den Übergang vom objektiven zum absoluten Geist sehr stark. Sie kann über das Ausgeführte hinaus an der bezeichneten Stelle sogar noch verstärkt werden.

2. Der Begriff des absoluten Geistes, der in der Begründung abgeleitet wird, legt durchgängig fest auf die zweite der oben genannten Alternativen, wie man das Absolut-, d.h. Abgelöstsein dieses Geistes verstehen kann: "absolut" heißt hier nicht bloß soviel wie "losgelöst von $[\ldots]^{\prime \prime}$, sondern auch "befreit zu [...] und vollendet" in den genannten Hinsichten, in denen eine innere Zweckmäßigkeit zum Vorschein kommt; losgelöst nämlich von bloßem Vorausgesetztsein der Natur und des jeweils anderen endlichen Geistes, aber eben damit befreit zur Einheit mit dem, was vorher bloß vorausgesetzt war.

3. Schon aus diesem Grund kann man einem letzten, in Habermas' Augen gewichtigsten (6.) Einwand gegen Hegel nicht beipflichten: Im Begriff des absoluten Geistes werde die zwischenmenschliche Intersubjektivität verdrängt. Soweit sie nichts Zufälliges ist, bleibt sie viel- 
mehr mit allem erhalten, was zur Freiheit als vorhandener Notwendigkeit gehört. Zusätzlich zu ihr aber wird im Begriff des absoluten Geistes eine weitere Intersubjektivität Thema: diejenige „zwischen“ dem endlichen und dem für sich unendlichen Geist als absoluter, aber selbst geistiger Substanz.

4. Der finitistische Verzicht, diese Intersubjektivität $\mathrm{zu}$ thematisieren, bekundet nicht bloß eine sympathische philosophische Zurückhaltung gegenüber religiösen Überzeugungen. Mit der üblichen Aversion gegen den Begriff eines Weltgeistes gepaart verdammt er die Philosophie auch zu einer Position, welche die mentalen Krankheiten unserer Zeit nicht mehr erfolgreich abwehren kann: den historistischen Nihilismus, den kulturalistischen Relativismus und den naturalistischen species-Chauvinismus in Bezug auf alle Bemühungen um Erkenntnis, vorab die philosophischen.

\section{Die Einleitung in die Lehre vom absoluten Geist (§553-555)}

Um Hegels Philosophie des absoluten Geistes recht $\mathrm{zu}$ verstehen, sollte man sich insbesondere klar machen, was ihre drei grundlegenden Paragraphen wollen und wie sie sich voneinander unterscheiden. Sie gliedern sich in eine Auskunft über die Einstellung, welche der begreifenden Erkenntnis des absoluten Geistes angemessen ist ( $\$ 553$ ); in die eigentliche Exposition des Begriffs solchen Geistes ( $\$ 554)$ und in eine Orientierung der Arbeit mit diesem Begriff. (§ 555) Ähnlich war Hegel schon zu Beginn der Naturphilosophie und zu Beginn der Philosophie des Geistes überhaupt verfahren. Nun befaßt er sich mit diesen drei Aufgaben in je einem Paragraphen. Was wird darin ausgeführt?

Schon der erste Satz von $\S 553$ kündigt an, was wir nicht mehr zu erwarten haben: "Der Begriff des Geistes hat seine Realität im Geiste". Die "Realisierung" des Begriffs wird uns also nicht über dessen Umfang hinaus $\mathrm{zu}$ anderer Realität als derjenigen führen, welche unter den Begriff des Geistes fällt, - im Unterschied zu allen Begriffen, deren Exposition und Realisierung bisher zu verfolgen war. Die neu in der Sphäre des Geistbegriffs zu berücksichtigende Realität ist das Wissen des absoluten Geistes. Die ihm entsprechende Einstellung begreifender philosophischer Erkenntnis muß, positiv bestimmt, nun darauf gerichtet werden, daß diese Realität „in vollendeter Identität mit jenem" 
Begriff (HEnc § 453), also in Wahrheit (und wohl auch in Identität speziell mit dem Begriff des absoluten Geistes) „als das Wissen der absoluten Idee sei“; als ein Wissen nämlich, wie "wir" es schon am Ende der "Logik" erlangt haben. Das entspricht bereits dem in $\S 382$ formell charakterisierten Wesen des Geistes als Freiheit und dem im $\S 552$ angegebenen Inhalt des Wissens als u.a. "Wahrheit, in welcher die wissende Vernunft frei für sich" ist. Aber es hat auch seine "notwendige Seite". Auf die kommt es nun an, sofern die Forderung, daß man sich in besonderer Weise auf philosophische Erkenntnis einstelle, zu begründen und inhaltlich näher zu bestimmen ist: Die "an sich", mithin der Möglichkeit nach, freie Intelligenz (vgl. $\S \S 443$ ff.) muß „in ihrer Wirklichkeit" (d. h. in der selbstbewußten Freiheit, die als Sitte zur Natur geworden ist, vgl. § 513) "zu ihrem Begriff befreit" sein, um die dieses Begriffs „würdige Gestalt zu sein“. (§ 553) Eine Würde nämlich besitzt nur, was höchsten intrinsischen Wert hat und dabei Ausdruck herrschenden Geistes ist. „Würdig“ darf heißen, was an so verstandener Würde Teil hat. Nur eine Wissensgestalt von solchem Wert ist völlig der Ehre angemessen, welche dem absoluten Geist als ewig wirklicher Wahrheit gebührt. Aber sie könnte nicht zustandekommen und begriffen werden ohne den bisher betrachteten subjektiven und objektiven Geist. Fern davon, für unsere Einstellung auf spekulativ begreifende Erkenntnis des absoluten Geistes irrelevant zu werden, sind beide, subjektiver und objektiver Geist, daher in der geforderten Einstellung nun "als der Weg anzusehen, auf welchem sich diese Seite [...] ausbildet". (Ebd.) So dienen sie mit der in ihnen enthaltenen Notwendigkeit geistiger Natur und Geschichte demjenigen Offenbarmachen des Geistes, welches Offenbarung des absoluten Geistes ist. Man wundere sich also nicht, in der Philosophie des absoluten Geistes auf neu gedeutete Bestimmungen des endlichen, subjektiven (insbesondere psychologischen) und objektiven (insbesondere weltgeschichtlichen) Geistes zu stoßen. Doch was dabei wie gedeutet wird, sagen vor allem die Ausführungen der "Encyclopädie", nicht die Vorlesungen über Religionsphilosophie.

Es liegt nahe zu fragen, ob des Begriffs der in ihrer Wirklichkeit zu diesem Begriff befreiten Intelligenz nur eine einzige Wissensgestalt "würdig" ist oder außer derjenigen des logischen Wissens der absoluten Idee in gewisser Weise noch andere Gestalten. Die Antwort kann nicht im Voraus gegeben werden. Sie hängt vom "Weg“ der Ausbildung ab, an deren Ende das Befreit-Sein in einem reinen Wissen stehen wird. So oder so aber wird auf diesen Weg zu achten sein. Wenn das 
klar ist, hat man keine Schwierigkeiten mehr, anhand der BegriffsAbleitung, die in $\S 552$ umrissen wurde, den Begriff des absoluten Geistes zu exponieren.

Darum geht es in $\S 554$. Hegels Angaben hierzu vermeiden wie schon bezüglich der absoluten Idee als logischer den Namen "Gott" und erst recht den Namen irgendeines besonderen Gottes. Sie können den Anspruch erheben, auch einen Atheisten zu überzeugen, wenn der sich ernsthaft auf die Argumente einläßt, welche bis zum Ende der Philosophie des objektiven Geistes geführt haben. Der absolute Geist ist nicht nur "ewige" (also nicht auf Zeit relative) "Wahrheit" (§ 552), d.h. Übereinstimmung des Begriffs in seiner Realität mit sich. Er ist als ewig wirkliche eine Wahrheit, die wie die absolute Idee "ebenso ewig in sich seyende als in sich zurückkehrende und zurückgekehrte" Übereinstimmung des Begriffs mit sich ist. Er ist diese Übereinstimmung wie die absolute Idee in der intensivsten Form als "Identität" (des Begriffs, in seiner Realität, mit sich als bloßem Begriff, vgl. § 553); und ist dabei, ebenfalls wie die absolute Idee, eine Identität, die auch Wissen ist: nicht mehr diese oder jene besondere sittliche Substanz nämlich mit bzw. in diesem oder jenem Fürwahrhalten; sondern die in sich unendliche "Eine und allgemeine Substanz als geistige". Als geistige Substanz ist er Freiheit (d.h. „,absolute Negativität des Begriffs als Identität mit sich", vgl. § 382), die sich ursprünglich teilt (also "das Urtheil" vollzieht) "in sich und in ein Wissen, für welches sie als solche ist". Das Wissen "des" absoluten Geistes ist also nicht nur eines "vom" absoluten Geist, das diesem gar bloß äußerlich wäre. Es gehört zu ihm selbst, auch als sein Sich-Wissen. Zudem ist der Prozeß der urspünglichen Teilung, ohne welchen das Wissen nicht wäre, und das im Prozeß von der Substanz unterschiedene, endliche Subjekt "zurückgebunden" in das Eine, das ja in sich zurückkehrt. Man kann diese ganze "Sphäre" geistiger Realität daher füglich als „Religion" (im allgemeinsten Sinn einer Rückbindung und rücksichtlichen Beachtung) bezeichnen. Aber man muß dabei bedenken: Die Religion geht nicht nur vom endlichen Subjekt (durch seine Erhebung zum Wissen des absoluten Geistes) aus und befindet sich nicht nur in diesem Subjekt als subjektivem Geist, während die Substanz jenseits und unberührt davon wäre. (Diesem verkürzten Religionsverständnis nämlich huldigen diejenigen, die den Inhalt der Religion preisgeben oder für unbestimmbar und beliebig erklären.) Die Religion ist ebenso zu betrachten „als objektiv von dem absoluten Geist ausgehend [...], der als Geist in seiner Gemeinde ist". Andernfalls könnte sie nicht jene Wissensgestalt ausbilden, für welche 
die an sich freie Intelligenz in ihrer objektiven, sittlichen Wirklichkeit zu ihrem Begriff befreit sein muß. Die Exposition des Begriffs kommt also nicht allein schon dadurch zustande, daß der zuvor (§ 552) abgeleitete Begriff analysiert wird. Sie hat auch die Einstellung (§ 553) zu berücksichtigen, die das philosophische Denken seinem Gegenstand gegenüber einnehmen muß.

Für die Arbeit mit dem exponierten Begriff wird (symmetrisch zum abzuwehrenden Mißverständnis) bereits im zweiten Satz des § 554 eine Anweisung gegeben: Man betrachte die "Religion" (= Rückbindung des Wissens an die Eine Substanz) nicht nur "objektiv" als vom absoluten Geist ausgehend, sondern eben so sehr als vom Subjekt ausgehend und in demselben sich befindend. Darauf verweist uns nicht zuletzt die Notwendigkeit (und Suche nach) einer „würdigen“ Gestalt jenes Wissens oder nach mehreren solchen Gestalten. Denn die wahrhafte Religiosität, die es zu entdecken gilt, ist "der freien Allgemeinheit ihres konkreten Wesens bewußt werdende Sittlichkeit". ( 5552 A, 2) Zur Orientierung der Begriffsarbeit ist daher nun das "subjektive Bewußtsein des absoluten Geistes" näher ins Auge zu fassen.

Das geschieht in $\S 555$, und zwar in doppelter Perspektive: sowohl im Blick darauf, was dieses Bewußtsein "in sich" ist bzw. subjektiv wird, als auch daraufhin, was mit ihm objektiv geschieht, sofern solches Geschehen für die Ausbildung würdiger Wissensgestalt relevant ist. Da es hierbei um eine "Sphäre", „d.h. Kugel und Kreisbahn, von Realitäten zu tun ist, die Bahn aber einen wohl-, wenn auch doppeltbestimmten Ausgangs- und Endpunkt hat, so daß das sie Durchlaufende wirklich "prozediert", wird man sich nicht wundern zu erfahren, dieses Bewußtsein sei "wesentlich in sich Prozeß"; und man wird die wahrhafte Religiosität sowie würdige Gestalt ihres Wissens am Ende dieses Prozesses zu erwarten haben.

Ein Prozeß nämlich ist mehr als bloß eine Bewegung von etwas, das einen Weg zurücklegt. Er ist seinem Begriff nach (§ 326) ein Vorgang der Differenzierung eines Identischen und/oder der Indifferentierung bzw. des Zusammenwachsens von Verschiedenem. Beides zusammen mag einen Kreislauf ergeben, der von einer unmittelbaren und "substantiellen" Einheit über Differenzierungen, Verhältnisse, vielleicht sogar Gegensätze zu vermittelter Einheit zurückführt, die eine "höhere" und konkretere als die ursprüngliche ist. Man darf die innere Zweckmäßigkeit, unter deren Begriff der absolute Geist zu denken ist, daher nicht zu simpel und harmonistisch konzipieren. Das gilt zweifellos auch für eine "an sich freie Intelligenz", die sich im subjektiven Be- 
wußtsein des absoluten Geistes auf dem Weg befindet, als welcher nun der subjektive und der objektive Geist anzusehen sind. Denn ganz zu Anfang, begrifflich sogar dem subjektiven Bewußtsein des absoluten Geistes vorausgehend, ist diese Intelligenz Selbstgefühl des in seiner sittlichen Substanz stehenden Subjekts und damit ein Zeugnis-Geben von dieser Substanz sowie von ihren Gewalten als von dem eigenen Wesen. In solchem Zeugnis des Geistes ist die Einheit des Subjekts mit seiner Substanz „unmittelbar noch identischer als selbst Glaube und Zutrauen". ( $R$ 147) Aber nicht weit von hier beginnt der begriffliche Weg des Prozesses, welcher das subjektive Bewußtsein des absoluten Geistes ist.

Die "unmittelbare und substantielle Einheit" dieses Prozesses nämlich ist "der Glaube in dem Zeugnis des Geistes als die Gewißheit von der objektiven Wahrheit". ( $(555,1$. Satz) Als Bewußtsein ist der Glaube jedoch nicht nur diese unmittelbare Einheit; sondern er "enthält" zugleich Einheit als das Verhältnis der im Begriff des absoluten Geistes unterschiedenen Bestimmungen einschließlich derjenigen von subjektiver Gewißheit und objektiver Wahrheit. Er ist also in sich der (begriffliche) Prozeß von substantieller Einheit zu deren Differenzierung in Verhältnisse. Unter spezifischen Bestimmungen solcher Verhältnisse mag das Glauben ein Wissen sein, das inhaltlich kein wahres, sondern bloß ein vermeintliches ist. Als solches kann es auch in Gegensatz kommen zur "geistigen Befreiung", die sich in der Sittlichkeit, im frei werdenden subjektiven Geist oder in anderen Realitätsbereichen des absoluten Geistes vollzieht. Aber im Hinblick auf wahrhafte Religiosität und eine würdige Gestalt ihres Wissens ist das nur ein Durchgangsstadium. Denn allemal ist der Glaube auch unmittelbare Einheit und als religiöser Vollzug dieser Einheit "re-unio". Jedenfalls in der $A n$ dacht, als einem „impliziten [...] Cultus", sowie in expliziteren Formen des Kultus, die in Sitte gewordenen Handlungen bestehen, ist er je schon in den gegenläufigen Prozeß übergegangen; und das gilt nicht nur in der Innenperspektive des religiösen Bewußtseins, sondern auch in Ansehung dessen, was diesem Bewußtsein objektiv geschieht: Durch den Kultus, wie z.B. den einer Opferhandlung, wird hervorgebracht, daß der Mensch sich seiner Subjektivität entledigt. (Vgl. XII, 236.) Dadurch wird ein "Gegensatz zur geistigen Befreiung", wenn sich ein solcher im Bewußtsein und seinen auf Gegenständliches Bezug nehmenden Betätigungen ausgebildet hat, im Prinzip wieder aufgehoben. Es wird "durch diese Vermittlung jene erste Gewißheit" bewährt. 
Tendenziell zumindest geht dieser Prozeß dahin, für die erste Gewißheit "die konkrete Bestimmung, nämlich die Versöhnung und Wirklichkeit des Geistes zu gewinnen". (§ 555, Schluß) Um im Begriff des absoluten Geistes die wahre Religiosität zu erkennen und deren Wissensgestalt als eine zu begreifen, die des Begriffs einer freien Intelligenz würdig ist, muß man also diese beiden, die wahrhafte Religiosität und ihre Wissensgestalt, am Ende eines Prozesses wie des umschriebenen aufsuchen. Die Religion vollendet sich als Sittlichkeit. (XII, 302) Die ihres Begriffs freier Intelligenz würdige Wissensgestalt kann sich daher nicht noch im Gegensatz zur Sittlichkeit befinden. Vielmehr ist in ihr nichts anderes als deren Grund im religiösen Glauben gewiß. Doch solange der Fortgang geistiger Befreiung nicht abgeschlossen ist, kann eine Wissensgestalt die Würde, die sie in der Wirklichkeit einer bestimmten sittlichen Epoche besitzt, in derjenigen einer anderen verlieren. Man tut also gut, sich für die Ausführung der Lehre vom absoluten Geist auf mehr als eine Gestalt solchen Wissens mit bewährter Glaubensgewißheit und auf die Ablösung einer Gestalt durch eine (oder mehr als eine) andere in einem geschichtlichen Prozeß einzustellen. Die Gründe dafür, daß das Denken oder auch die Weltgeschichte von einer Gestalt solchen Wissens zu einer anderen fortgeht, sind im skizzierten Kontext zu suchen. Man findet sie ausschließlich auf dem sozusagen zweibahnigen "Weg", als welcher der subjektive und der objektive Geist weiterhin anzusehen sind.

Doch bevor man sie mit Sinn suchen kann, muß bereits eine erste, unmittelbare Gestalt gefunden sein. Da deren Bestimmung nicht diejenige des Begriffs absoluten Geistes als solchen ist, gehört sie nicht mehr zu unserem Thema. Aber worin sie wohl bestehen muß und was auf sie folgen wird, wäre nun unschwer zur Einteilung der Entwicklung des Begriffs wenigstens im Umriß anzugeben: Sie muß jedenfalls eine sein, die in der Abfolge begriffsadäquater sittlicher Welten als die erste auftrat. Sie muß ferner in ihrer sittlichen Welt unmittelbar realisiert gewesen; und die absolute Einheit des Geistes mit sich muß dabei in Tätigkeiten des subjektiven Geistes auf unmittelbare Weise, d.h. anschauend, vollzogen worden sein. - Auf sie mußte wohl eine Gestalt folgen, die erst durch den Untergang dieser "schönen" sittlichen Welt möglich geworden sein wird. Sie wird die eines sich in sich vermittelnden Wissens in einer durch und durch mittelbaren, d.h. vorstellenden Tätigkeit des subjektiven Geistes sein müssen. Aber würdig des Begriffs, zu welchem die an sich freie Intelligenz in ihrer Wirklichkeit befreit ist und so zum Wissen der absoluten Idee führend, wird diese Ge- 
stalt erst werden, wenn sie in einem selbstbewußten philosophischen Denken die früher entstandenen Tätigkeiten, den Geist ",absolut" anzuschauen und vorzustellen, in sich vereinigt. Nicht die Vorlesungen, sondern nur die betrachteten einleitenden Paragraphen machen Hegels Philosophie des absoluten Geistes als ganze begreiflich.

IV. Anhang: Schema der Hegelischen Bestimmungen des Ausgangszustands und Endpunkts denkender Erhebung

\begin{tabular}{|c|c|c|}
\hline Angegeben wird: & Ausgangszustand & Endpunkt \\
\hline 1 Das Ganze & $\begin{array}{l}\text { Der Volksgeist } \\
\text { - enthält Naturnotwendig- } \\
\text { keit } \\
\text { [die das Opake, im endlichen } \\
\text { Geist funktionslos Vorausge- } \\
\text { setzte ist] } \\
\text { - steht in äußerlichem Da- } \\
\text { sein }\end{array}$ & $\begin{array}{l}\text { [der absolute Geist] } \\
\text { - [worin Natur-] Notwen- } \\
\text { digkeit nur seiner Offenba- } \\
\text { rung dienend [ist] (G) } \\
\text { - [ist Wahrheit], in welcher } \\
\text { die wissende Vernunft frei } \\
\text { für sich ist }(\mathrm{G})\end{array}$ \\
\hline $\begin{array}{l}2 \text { Binnenstruktur } \\
\text { a objektive Seite }\end{array}$ & $\begin{array}{l}\text { die sittliche Substanz } \\
\text { - in sich [= abgesehen v. } \\
\text { Grenze nach außen, = zuin- } \\
\text { nerst, in sich verschlossen?] } \\
\text { unendlich } \\
\text { - für sich eine besondere } \\
\text { und beschränkte }\end{array}$ & $\begin{array}{l}\text { [die Unendlichkeit ist im } \\
\text { Wissen herausgetreten] (G) } \\
\text { - [mit dem denkenden } \\
\text { Geist, der] konkrete Allge- } \\
\text { meinheit }(\mathrm{G}), \text { [sind] Be- } \\
\text { schränktheiten der besonde- } \\
\text { ren Volksgeister abgestreift } \\
\text { (G) }\end{array}$ \\
\hline b subjektive Seite: & $\begin{array}{l}\text { - mit Zufälligkeit behaftet } \\
\text { [einerseits:] } \\
\quad \text { - - bewußtlose Sitte } \\
\text { [andererseits:] } \\
\quad-\text { - Beww } 3 \text { stsein des In- }\end{array}$ & $\begin{array}{l}\text { [Zufälligkeit ist mit Beson- } \\
\text { derheiten abgestreift, außer } \\
\text { Freiheit besteht nur noch } \\
\text { Notwendigkeit] (G) } \\
\text { [nichts Bewußtloses] [G] } \\
\text { [nicht Bewußt-, sondern }\end{array}$ \\
\hline
\end{tabular}




\begin{tabular}{|c|c|c|}
\hline c punctum saliens in b: & $\begin{array}{l}\text { halts } \\
\text { [der Sitte, der subj. Seite, der } \\
\text { sittl. Substanz?] } \\
\text { - als eines zeitlich Vor- } \\
\text { handenen } \\
\text { - im Verhältnisse gegen } \\
\text { eine äußerliche Natur } \\
\text { und Welt } \\
\\
\text { der denkende Geist } \\
\text { - in der Sittlichkeit, } \\
\text { welcher als Volksgeist } \\
\text { Endlichkeit hat } \\
\text { - der Weltgeschichte }\end{array}$ & $\begin{array}{l}\text { Erfaßt- und Erhobensein } \\
\text { zu der] (G) } \\
\text { - ewig wirklichen } \\
\text { Wahrheit [die Übereinstim- } \\
\text { mung mit sich ist u. nicht im } \\
\text { Verh. geg. ein Anderes, Äu- } \\
\text { Berliches] (G) } \\
\text { Wissen } \\
\text { des } \\
\text { absoluten Geistes (V) } \\
\text { Weltlichkeit abgestreift (G) }\end{array}$ \\
\hline 3 wieder das Ganze: & $\begin{array}{l}\text { [obj. sittl. Substanz u. subj. } \\
\text { Gesinnung als zwei Seiten } \\
\text { oder Teile] } \\
\text { Notwendigkeit [in der vor- } \\
\text { ausgesetzten] Natur [und in } \\
\text { dem] zeitlichen Systeme der } \\
\text { Gesetze und der Sitten [also } \\
\text { auch in der Geschichte] [be- } \\
\text { sitzt Substantialität] }\end{array}$ & $\begin{array}{l}\text { [„des“ als Genitiv, der so- } \\
\text { wohl subjektiv als auch ob- } \\
\text { jektiv; vgl. die nachfolgende } \\
\text { Apposition; mit Gewußtem / } \\
\text { Wissendem:] als der ewig } \\
\text { wirklichen Wahrheit, in wel- } \\
\text { cher die wissende Vernunft } \\
\text { frei für sich [ist] und } \\
\text { Notwendigkeit, Natur und } \\
\text { Geschichte nur seiner [sc. } \\
\text { des absoluten Geistes] Of- } \\
\text { fenbarung dienend und Ge- } \\
\text { fäß seiner Ehre. (G) }\end{array}$ \\
\hline
\end{tabular}

Legende: kursiv: Hegels Worte; fett und kursiv: bei Hegel hervorgehoben; in „[] [“: meine Zusätze

(G): Gegenbestimmung zu dem links auf Höhe der Eintragung stehenden Ausdruck

(V): Vollendungsalternative zu dem links stehenden Ausdruck 